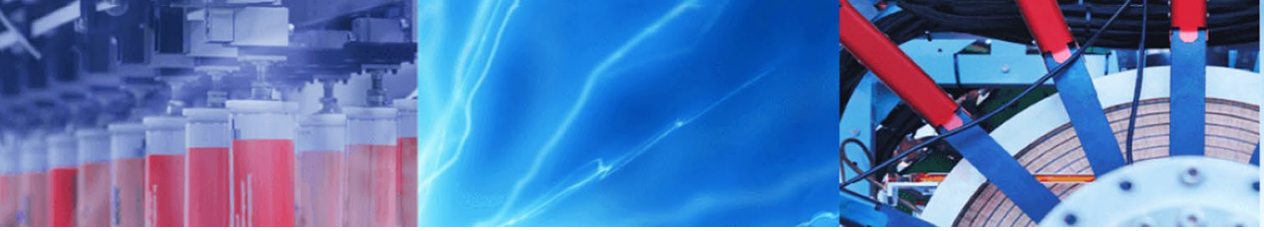

Research Article

\title{
2,4-Dichlorophenoxyacetic acid adsorption on montmorillonite organoclay for controlled release applications
}

\author{
Caio Vinicius Lima Natarelli ${ }^{1} \cdot$ Pedro Ivo Cunha Claro ${ }^{2} \cdot$ Kelvi Wilson Evaristo Miranda ${ }^{1}$. \\ Guilherme Max Dias Ferreira ${ }^{3}$. Juliano Elvis de Oliveira ${ }^{4}\left[\right.$ J José Manoel Marconcini $^{5}$
}

(c) Springer Nature Switzerland AG 2019

\begin{abstract}
2,4-Dichlorophenoxyacetic acid (2,4-D) is one of the most used herbicides for weed control. However, the use of large concentrations of 2,4-D is dangerous and have great carcinogenic potential. Thus, this work evaluated the 2,4-D sorption behavior by an organically modified montmorillonite nanoclay using kinetic and thermodynamic approaches. Adsorption isotherms and kinetic studies, conducted under controlled temperature and $\mathrm{pH}$ conditions, indicated a high capacity of the nanoclay to remove 2,4-D from aqueous medium, being that the adsorption mechanism probably involved physisorption and chemisorption. Besides, thermodynamic parameters obtained showed that the adsorption was enthalpically driven for the physisorption step, with $\Delta H^{\circ}=-9.849 \mathrm{~kJ} \mathrm{~mol}^{-1}$. The analyses showed that 2,4-D adsorption caused a partial exfoliation of the montmorillonite structure, probably due to the high herbicide concentration utilized. Release studies of 2,4-D from the nanoclay showed that the desorption process occurred in two steps, a burst release of the 2,4-D molecules followed by a slow release. The results demonstrated by this study indicates the feasibility of the proposed system for controlled release or even water treatment applications.
\end{abstract}

Keywords Organically modified nanoclay $\cdot$ Herbicide $\cdot$ Adsorption studies $\cdot$ Controlled release $\cdot$ Agriculture applications

\section{Introduction}

Montmorillonite is a cheap, abundant and natural 2:1 phyllosilicate clay belonging to the smectites group. This clay has a crystal structure composed by two silica tetrahedral sheets with one alumina octahedral sheet between them, besides the presence of the interlayer region that contains interchangeable cations and water molecules [1-3]. The members of the smectite group possess important sorptive properties due to their large specific surface area and high structural charge [4]. To enhance the sorptive properties of these clays, the modification also known as organophilization can be realized with cationic surfactants, such quaternary ammonium salts, as modifiers [5, 6]. This enhancement widens the application range of the montmorillonite as an adsorbent material, increasing its efficiency in controlled release systems (CRS), water treatment, gas separation applications, and others process of environmental and purification purposes $[6,7]$.

The use of modified clays in CRS for agriculture applications is widely reported in the literature [8-10]. Rytwo and Moshe [8] reported the use of montmorillonite modified

Electronic supplementary material The online version of this article (https://doi.org/10.1007/s42452-019-1235-4) contains supplementary material, which is available to authorized users.

Juliano Elvis de Oliveira, juliano.oliveira@deg.ufla.br| ${ }^{1}$ Graduate Program in Biomaterials Engineering, UFLA - Universidade Federal de Lavras, Lavras, Minas Gerais, Brazil. ${ }^{2}$ Graduate Program in Materials Science and Engineering, UFSCar - Universidade Federal de São Carlos, São Carlos, São Paulo, Brazil. ${ }^{3}$ Department of Chemistry, UFLA - Universidade Federal de Lavras, Lavras, Minas Gerais, Brazil. ${ }^{4}$ Department of Engineering, UFLA - Universidade Federal de Lavras, Lavras, Minas Gerais, Brazil. ${ }^{5}$ National Nanotechnology Laboratory for Agriculture (LNNA), EMBRAPA Instrumentation, São Carlos, São Paulo, Brazil. 
with quaternary ammonium salts, such octadecyltrimethylammonium (ODTMA) and berberine, and other modifiers for the controlled release of allyl isothiocyanate (AITC), mustard oil major component used in the agriculture as fumigant in the control of insects. The montmorillonite modification increased by at least $60 \%$ the time release of AITC. Tejada et al. [9] studied the use of Na-montmorillonite modified with phosphatidylcholine (PC) for controlled release of the herbicides diuron and alachlor in soils. The dissipated amount of the herbicides in the soils using the PC-clay formulations was lower when compared with the direct herbicide application, mainly for alachlor in the first 16 days of incubation. In another study, Tchoumene et al. [10] reported the controlled release of methyl viologen (MV), a herbicide commercially known as paraquat, from clay formulations utilizing kaolinite modified with $\mathrm{N}$-methylformamide as precursor. The MV was freed from the kaolinite formulations in a slow behavior with approximately $85 \%$ of MV during 70 min.

One of the most utilized herbicides in the world is the 2,4-Dichlorophenoxyacetic acid (2,4-D), which is used for weed control in terrestrial environments, such as cultivations of maize, soya, sugar cane, rice and wheat in the agriculture, and aquatic ones, via spraying of 2,4-D in water solution [11-13]. When utilized in low concentrations, 2,4-D can be used as a phytohormone, as it is considered a synthetic auxin [14]. However, despite 2,4-D wide utilization, it has been proven that 2,4-D is a toxic and potentially carcinogenic product with low effectiveness in reaching the target weeds, where most of the herbicide used end up in the water streams and soils $[12,14]$. Whereas 2,4-D adsorption on pure montmorillonite has been widely studied in the past, Weber et al. [15], Haque et al. [16] and Ogram et al. [17] did not note significant results in their studies. However, more recently, Bhardwaj et al. [12] analyzed 2,4-D adsorption and release, but through leaching studies simulating direct soil application from various clays materials, they verified that the organophilization of most materials, including organically modified montmorillonite, improved the adsorption capacity and enabled its use in controlled release systems. As it is a good alternative to prevent product losses, the use of CRS where the active ingredient is trapped in the system matrix and released over time, increases the product effectiveness [18].

Focusing on the development of a controlled release system intended to improve the spraying application effectiveness, i.e., a CRS on aqueous solution, the 2,4-D adsorption by an organically modified montmorillonite nanoclay and release studies were realized. Adsorption studies were conducted varying the temperature and $\mathrm{pH}$ conditions to evaluate and determine the best process conditions, with the auxilium of the most utilized isotherm and kinetic models. $\mathrm{N}_{2}$ adsorption, DRX and FTIR analyses were realized to evaluate the interactions resultants from the 2,4-D adsorption. Furthermore, the herbicide release profile from the nanoclay was analyzed.

\section{Experimental}

\subsection{Materials}

Organically modified montmorillonite nanoclay of commercial grade (Cloisite 30B), which is modified with methyl tallow bis(2-hydroxyethyl) quaternary ammonium salt, was supplied by Southern Clay Products, Inc. (Texas, USA). 2,4-Dichlorophenoxyacetic acid powder with a minimum purity of $98 \%$ was supplied by Aldrich Chemistry (USA).

\subsection{Adsorption studies}

Adsorption amount of 2,4-D on the nanoclay was determined by depletion method as follow described. The adsorption isotherm studies were performed in $50 \mathrm{~mL}$ conical tubes containing $80 \mathrm{mg}$ of nanoclay dispersed in $40 \mathrm{~mL}$ of aqueous solution of ethanol $(3 \% \mathrm{v} / \mathrm{v})$, i.e., $2 \mathrm{mg} \mathrm{mL}^{-1}$ of montmorillonite, and $4.40-35.50 \mathrm{mg}$ of 2,4-D $\left(500-4000 \mu \mathrm{mol} \mathrm{L}^{-1}\right)$. The $\mathrm{pH}$ of the aqueous solutions was previously adjusted to 2 , as defined by preliminary zeta potential characterization (Supporting information S1), utilizing $\mathrm{HCl}$ and $\mathrm{KOH}$ solutions. Additionally, the temperature influence was evaluated on the isotherm studies in different conditions $\left(25,35\right.$ and $\left.45 \pm 1^{\circ} \mathrm{C}\right)$. The experiments were conducted in a water bath orbital shaker (Ethik Technology 501-DE) at $150 \mathrm{rpm}$. After the equilibrium time, set to $120 \mathrm{~min}$ by preliminary experiments, an aliquot of $4 \mathrm{~mL}$ was taken, centrifuged at $3600 \mathrm{rpm}$, and analyzed using UV-vis spectroscopy to measure the 2,4-D equilibrium concentration $C_{e}\left(\mathrm{mg} \mathrm{L}^{-1}\right)$. The spectrophotometric measurement was realized using a calibration curve. The 2,4-D adsorption amount when the equilibrium was reached, $q_{e}$ $\left(\mathrm{mg} \mathrm{g}^{-1}\right)$, could be calculated by Eq. (1):

$q_{e}=\frac{\left(C_{0}-C_{e}\right) V}{m}$

in which $C_{0}\left(\mathrm{mg} \mathrm{L}^{-1}\right)$ is the 2,4-D initial concentration, $V$ $(\mathrm{L})$ is the solution volume, and $m(\mathrm{~g})$ is the nanoclay mass.

Four isotherm models were applied to describe the adsorption process of the herbicide on the nanoclay: the Langmuir, the Freundlich, the Dubinin-Radushkevich, and the Partition models. While the Langmuir model assumes a monolayer coverage of adsorbate on the surface of the adsorbent, in which there is a finite number of identical adsorption sites that can interact with the adsorbate, Freundlich model assumes that the adsorption process occurs 
on a heterogeneous surface [19-22]. The Dubinin-Radushkevich model is a more general model in which the assumption is not based on a homogeneous surface or a constant adsorption potential, but it is applicable to systems that have heterogeneous surfaces with a Gaussian energy distribution [23, 24]. The Langmuir, the Freundlich, and the Dubinin-Radushkevich are described by Eqs. (2)-(4), respectively:

$q_{e}=\frac{q_{m} K_{L} C_{e}}{1+K_{L} C_{e}}$

$q_{e}=K_{F} C_{e}^{1 / n}$

$q_{e}=q_{D} \exp \left(-\beta\left[R T \ln \left(1+\frac{1}{c_{e}}\right)^{2}\right]\right)$

in which $q_{m}\left(\mathrm{mg} \mathrm{g}^{-1}\right)$ is the Langmuir maximum adsorption amount, $K_{L}\left(\mathrm{~L} \mathrm{mg}^{-1}\right)$ is the Langmuir constant associated to the adsorbate-site interaction, $K_{F}\left(\mathrm{~L} \mathrm{~g}^{-1}\right)$ and $n$ are Freundlich constants related to the adsorption capacity and intensity of the adsorption, respectively, $q_{D}\left(\mathrm{mg} \mathrm{g}^{-1}\right)$ is the Dubinin-Radushkevich maximum adsorption capacity, $\beta$ $\left(\mathrm{mol}^{-2} \mathrm{~J}^{-2}\right)$ is the activity coefficient, $R\left(\mathrm{~J} \mathrm{~mol}^{-1} \mathrm{~K}^{-1}\right)$ is the universal gas constant, and $T(\mathrm{~K})$ is the temperature.

The partition model, a special case of the Freundlich equation, is presented in Eq. (5), in which $K_{p}\left(\mathrm{~L} \mathrm{~g}^{-1}\right)$ is the partition coefficient. It is a linear model, easy-to-use approximation, where the ratio between the concentration of the compound remaining in solution and adsorbed on the solid is the same at any concentration [25].

$q_{e}=K_{p} C_{e}$

From the isotherms at different temperatures, the best adsorption condition (temperature and 2,4-D concentration) was selected, and the adsorption kinetic studies were performed in $250 \mathrm{~mL}$ Erlenmeyer flasks containing $200 \mathrm{mg}$ of nanoclay dispersed in $100 \mathrm{~mL}$ of aqueous solution of ethanol $(3 \% \mathrm{v} / \mathrm{v})$, at $25 \pm 1{ }^{\circ} \mathrm{C}$, and $\mathrm{pH}$ adjusted to 2,3 or 4 , as defined by the zeta potential characterization. At preset time intervals, an aliquot of $4 \mathrm{~mL}$ was taken, centrifuged at $3600 \mathrm{rpm}$, and analyzed to measure the 2,4-D concentration, $C_{t}\left(\mathrm{mg} \mathrm{L}^{-1}\right)$, using spectrophotometric method. The 2,4-D uptake at any time $t, q_{t}\left(\mathrm{mg} \mathrm{g}^{-1}\right)$, was calculated by Eq. (6):

$q_{t}=\frac{\left(C_{0}-C_{t}\right) v}{m}$

To better understand the mechanisms involved in the 2,4-D adsorption and to select the $\mathrm{pH}$ in which the maximum adsorption occurs, three kinetic models were used (pseudo-first-order, pseudo-second-order, and intraparticle diffusion model). The main difference between these models is based in the assumptions which one makes. The pseudo-first-order model assumes that the adsorption rate is directly proportional to the difference between the adsorbed amount of adsorbate in the time $t$ and at the equilibrium time, being the process a physisorption. The pseudo-second-order model considers that the adsorption rate is proportional with the square of difference between the amount of adsorbate adsorbed with time and at equilibrium, being the process a chemisorption [26-28]. As for the intraparticle diffusion model, it is often used when the adsorbent is a porous material, assuming that the intraparticle diffusion rate is limiting step for the process $[28,29]$. The pseudo-first-order, the pseudo-second-order, and the intraparticle diffusion models are described in Eqs. (7)-(9):

$q_{t}=q_{e}\left(1-\exp \left(-k_{1} t\right)\right)$

$q_{t}=\frac{q_{e}^{2} k_{2} t}{1+k_{2} q_{e} t}$

$q_{t}=k_{i d} t^{0.5}+C$

in which $k_{1}\left(\mathrm{~min}^{-1}\right), k_{2}\left(\mathrm{mg} \mathrm{g}^{-1} \mathrm{~min}^{-1}\right)$, and $k_{\text {id }}\left(\mathrm{mg} \mathrm{g}^{-1} \mathrm{~min}^{-0.5}\right)$ are the adsorption rate constants of the pseudo-first-order, pseudo-second-order and intraparticle diffusion model, respectively, and $C\left(\mathrm{mg} \mathrm{g}^{-1}\right)$ is the intercept of the plot obtained from the model. The intercept gives a notion about the thickness of the boundary layer, i.e., the larger the value of the intercept, the greater the boundary layer effect [30].

\subsection{Characterization of the system}

With the selection of the best conditions $(\mathrm{pH}$ and temperature) for the 2,4-D adsorption, the conditions were reproduced at $150 \mathrm{rpm}$ with $2 \mathrm{mg} \mathrm{mL}^{-1}$ of nanoclay and $4000 \mu \mathrm{mol} \mathrm{L}^{-1}$ of $2,4-\mathrm{D}$. Then, when the equilibrium was reached (approximately $120 \mathrm{~min}$ ), the sample with 2,4-D adsorbed was filtered by vacuum, oven dried at $60^{\circ} \mathrm{C}$ (FANEM 320-SE) and, then, characterized. Also, a nanoclay control sample was submitted to the same adsorption conditions without 2,4-D and characterized along with a pristine montmorillonite sample to verify if the process and the obtaining method induces any changes to the montmorillonite.

\subsubsection{Adsorption efficiency}

After the vacuum filtration, the filtered solution was centrifuged, and the supernatant concentration was measured spectrophotometrically. The adsorption efficiency (AE) of the 2,4-D on the nanoclay, in percentage, was calculated in triplicate using the Eq. (10).

$A E=\frac{\left(C_{0}-C_{e}\right)}{C_{0}} \times 100$ 


\subsection{2 $\mathrm{N}_{2}$ adsorption analysis}

Specific surface area and porosity of the samples was measured using nitrogen adsorption at $77 \mathrm{~K}$ with a Micromeritics ASAP 2020. The Brunauer-Emmett-Teller (BET) specific surface area $S_{B E T}$ was obtained between 0.05 and 0.22 relative pressure $\left(P / P_{0}\right)$, the porosity parameters were obtained in the adsorption branch of the hysteresis, where the total pore volume was estimated by total adsorption at $P / P_{0} \approx 0.98$ and the average pore diameter was calculated through $4 \mathrm{~V} / S_{B E T}$.

\subsubsection{Structural analysis}

In order to study the 2,4-D adsorption effects on the structure of the montmorillonite, X-ray diffraction (XRD) and Fourier transform infrared spectroscopy (FTIR) were utilized. Powder X-ray diffraction patterns were recorded between $4^{\circ}$ and $12^{\circ}$ on a Shimadzu XRD-600 diffractometer with Cu Ka radiation $(\lambda=1.5406 \AA$ ) operating at $30 \mathrm{kV}$ and $30 \mathrm{~mA}$ using a step size of $0.02^{\circ}$. From the XRD patterns, the basal spacing of the samples was calculated using Bragg's law $(n \lambda=2 d \operatorname{sen} \theta)$ on the position of the (001) reflection. Fourier transform infrared spectroscopy (FTIR) in transmittance mode was used to obtain the samples spectra, with a Bruker Vertex 50 spectrometer and utilizing the $\mathrm{KBr}$ method. The analysis was conducted in the range of $4000-400 \mathrm{~cm}^{-1}$, using a resolution of $4 \mathrm{~cm}^{-1}$, and 32 scans per spectra.

\subsection{Release study}

Experiments were conducted in $250 \mathrm{~mL}$ Erlenmeyer flasks containing approximately $550 \mathrm{mg}$ of the 2,4-D/ nanoclay sample dispersed in $100 \mathrm{~mL}$ of aqueous solution of ethanol $(3 \% \mathrm{v} / \mathrm{v})$ at $25 \pm 1{ }^{\circ} \mathrm{C}, \mathrm{pH} 6$ (as described by the zeta potential characterization) and $150 \mathrm{rpm}$, in the water bath orbital shaker, following the method described in the literature with some modifications [31], as follow described. At preset time intervals, an aliquot of $4 \mathrm{~mL}$ was taken and centrifuged at $3600 \mathrm{rpm}$ to measure, from the supernatant, the 2,4-D concentration released, $C A_{r}\left(\mathrm{mg} \mathrm{L}^{-1}\right)$, by the nanoclay. The measure was realized spectrophotometrically at $283 \mathrm{~nm}$, and then, the aliquot was homogenized with a vortex mixer (Bionex $\mathrm{KMC}-1300 \mathrm{~V}$ ) and returned to the medium. The 2,4-D cumulative release $(C R)$, in percentage, was calculated using Eq. (11):

$C R=\frac{C A_{r}}{C A_{0}} \times 100$ in which $C A_{0}\left(\mathrm{mg} \mathrm{L}^{-1}\right)$ is the 2,4-D initial concentration present on the nanoclay.

To better understand the 2,4-D release mechanism from the formulation, the model dependent approach was applied using the models of Weibull, Logistic and Makoid-Bakanar. These models are empiric ones that were adapted to the dissolution/release process and can be successfully applied to almost all kinds of release curves, but in return, these models were not deducted from any kinetic fundament [32-35]. The Weibull, Logistic and Makoid-Bakanar models are described by Eqs. (12)-(14):

$\frac{M}{M_{0}}=1-\exp \left(\frac{-\left(t-T_{l}\right)^{b}}{a}\right)$

$\frac{M}{M_{0}}=\frac{\exp ((a+b) \log (t))}{1+\exp ((a+b) \log (t))}$

$\frac{M}{M_{0}}=k_{M B} t^{n} \exp (-k t)$

where $M / M_{0}$ is the fractional cumulative release at time $t$ ( $\mathrm{min}), T_{1}(\mathrm{~min})$ is the time lag before the onset of the process, $a$ is a scale parameter that describes the time dependence, $b$ is a parameter that describes the release curve shape, $k_{M B}, n$, and $k$ are empirical parameters in the Makoid-Banakar model.

\subsection{Statistical analysis}

The quality and the accuracy of the fitted models and its respective parameters were measured through the analysis and comparison of the coefficient of determination $R^{2}$, the Chi square $\chi^{2}$ and the average relative error (ARE). Also, the Akaike information criterion $(A / C)$ was utilized to verify the reliability of the applied models [36]. These comparison parameters were obtained by the Eqs. (15)-(18):

$R^{2}=\left(\frac{\sum_{i=1}^{n}\left(q_{i, \text { exp }}-\bar{q}_{i, e x p}\right)^{2}-\sum_{i=1}^{n}\left(q_{i, e x p}-q_{i, \text { odel }}\right)^{2}}{\sum_{i=1}^{n}\left(q_{i, \text { exp }}-\bar{q}_{i, e \times p}\right)^{2}}\right)$

$\chi^{2}=\sum_{i=1}^{n} \frac{\left(q_{i, \text { exp }}-q_{i, \text { mode }}\right)^{2}}{q_{i, \text { model }}}$

$A R E=\frac{100}{N} \sum_{i=1}^{n}\left|\frac{q_{i \text { model }}-q_{i, \mathrm{exp}}}{q_{i, \mathrm{exp}}}\right|$

$A I C=N \ln \left(\frac{S S E}{N}\right)+2 p+\frac{2 p(p+1)}{N-P-1}$

where $q_{i, \text { exp }}$ is each value of $q$ obtained experimentally, $\bar{q}_{i, \exp }$ is the average value of all $q_{i, \exp }$ that were obtained, $q_{i, \text { model }}$ is each value of $q$ predicted by the model used, $N$ is the number of experimental points, $p$ is the number of 
parameters of the model and SSE is sum of squared errors, that can be obtained by the Eq. (19).

SSE $=\sum_{i=1}^{n}\left(q_{i, \text { model }}-q_{i, \text { exp }}\right)^{2}$

\section{Results and discussion}

\subsection{Adsorption studies}

\subsubsection{Isotherms}

The interaction between the adsorbate and the adsorbent in the equilibrium condition was studied to define the highest initial concentration that results in the highest adsorption capacity before the adsorbent saturation. The adsorption isotherms obtained at $\mathrm{pH} 2$ and temperature of 25,35 , and $45^{\circ} \mathrm{C}$ are shown in Fig. 1 .

Analyzing the isotherms shapes from the data points and comparing them to the Giles et al. [37] classification, the isotherm at $25^{\circ} \mathrm{C}$ (Fig. 1a) can be classified as a L-type, sub group 3, presenting an exponential shape when $C_{e}$ values increased up to $280.707 \mathrm{mg} \mathrm{L}^{-1}$. However, from this concentration, $q_{e}$ value comes back to increase and no surface saturation is reached in the concentration range investigated, indicating a multilayer formation on the adsorbent [38]. With the increase in temperature, the shape of the isotherms changes and, at $45^{\circ} \mathrm{C}$ (Fig. 1C), becoming a $\mathrm{C}$-type curve, sub group 1 , in which it has a linear shape and it occurs when the adsorbate has more affinity with the adsorbent than with the solvent [37]. As for the higher experimental adsorption capacity, observed when 2,4-D initial concentration was $35.50 \mathrm{mg}\left(4000 \mu \mathrm{mol} \mathrm{L}^{-1}\right)$, it slightly reduces from $282.87 \pm 1.52$ to $278.77 \pm 3.03$, and $275.69 \pm 3.16 \mathrm{mg} \mathrm{g}^{-1}$ when the temperature is increased from 25 to 35 , and $45^{\circ} \mathrm{C}$, respectively. This result indicates that despite the change in the isotherm shape to one with more affinity (C-type) when temperature increases, the adsorption capacity of the nanoclay is slightly affected.

The fitted models for the experimental data are also plotted in Fig. 1, and the adjustment parameters obtained from each model are in Table 1. Through the statistical comparison parameters, the application of the Dubinin-Radushkevich model to the experimental data was not very successful as the coefficient of determination $R^{2}$ was the lowest. The Freundlich model was the best fitted, as it presented the higher values of coefficient of determination $R^{2}$ and the lowest values of Chi square $\chi^{2}, A R E$ and $A I C$, closely followed by the Langmuir model. The proximity of the statistical parameters probably means that both models simultaneously or a model mixture describes the experimental data. However, because the nanoclay is formed by distinct
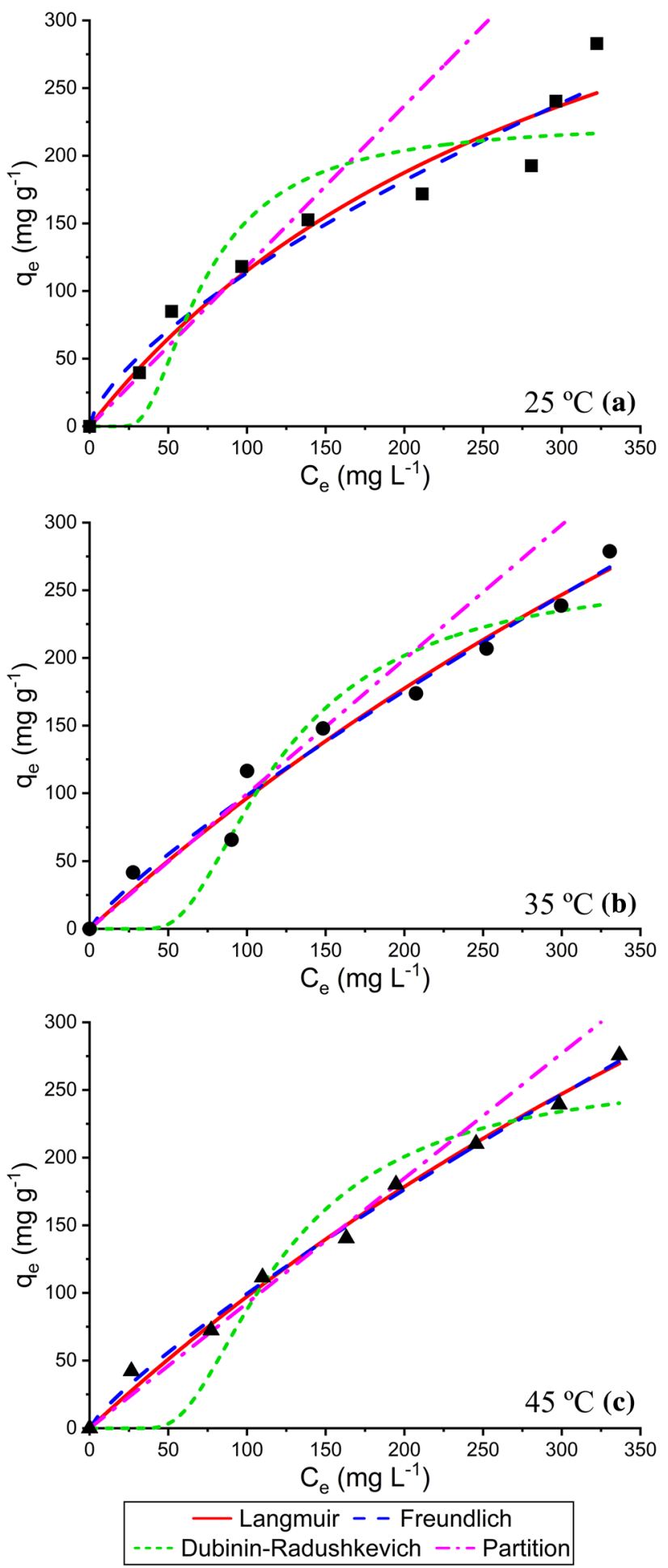

Fig. 1 Adsorption isotherms data of 2,4-D on the montmorillonite at $\mathrm{pH} 2$ and temperatures of 25 (a), 35 (b) and $45^{\circ} \mathrm{C}$ (c) fitted to the Langmuir, Freundlich, Dubinin-Radushkevich and partition models (the partition model was fitted only for the first five experimental points) 
Table 1 Parameters of the Langmuir, Freundlich, Dubinin-Radushkevich and partition models applied to the 2,4-D adsorption on the montmorillonite at the temperatures of 25,35 and $45^{\circ} \mathrm{C}$

\begin{tabular}{|c|c|c|c|c|}
\hline \multirow[t]{2}{*}{ Model } & \multirow[t]{2}{*}{ Parameter } & \multicolumn{3}{|c|}{ Temperature $\left({ }^{\circ} \mathrm{C}\right)$} \\
\hline & & 25 & 35 & 45 \\
\hline \multirow[t]{6}{*}{ Langmuir } & $q_{m}\left(\mathrm{mg} \mathrm{g}^{-1}\right)$ & 506.21 & 1116.80 & 1067.51 \\
\hline & $K_{L}\left(\mathrm{~L} \mathrm{mg}^{-1}\right)$ & 0.003 & 0.001 & 0.001 \\
\hline & $R^{2}$ & 0.947 & 0.978 & 0.993 \\
\hline & $\chi^{2}$ & 19.300 & 18.286 & 9.357 \\
\hline & ARE (\%) & 10.645 & 13.312 & 7.620 \\
\hline & $A I C$ & 55.194 & 48.517 & 39.012 \\
\hline \multirow[t]{6}{*}{ Freundlich } & $K_{F}\left(\mathrm{Lg}^{-1}\right)$ & 4.983 & 2.104 & 2.209 \\
\hline & $n$ & 1.474 & 1.197 & 1.209 \\
\hline & $R^{2}$ & 0.955 & 0.980 & 0.995 \\
\hline & $\chi^{2}$ & 17.452 & 13.960 & 4.470 \\
\hline & $A R E(\%)$ & 12.446 & 11.740 & 6.384 \\
\hline & $A / C$ & 53.985 & 47.679 & 36.677 \\
\hline \multirow{6}{*}{$\begin{array}{l}\text { Dubinin- } \\
\text { Radushk- } \\
\text { evich }\end{array}$} & $q_{D}\left(\mathrm{mg} \mathrm{g}^{-1}\right)$ & 225.00 & 265.49 & 265.04 \\
\hline & $\beta\left(\mathrm{mol}^{-2} \mathrm{~J}^{-2}\right)$ & 0.001 & 0.002 & 0.002 \\
\hline & $R^{2}$ & 0.842 & 0.922 & 0.919 \\
\hline & $\chi^{2}$ & 308.949 & 22.189 & 37.150 \\
\hline & $\operatorname{ARE}(\%)$ & 29.344 & 22.467 & 25.207 \\
\hline & $A / C$ & 63.967 & 58.638 & 58.854 \\
\hline \multirow[t]{5}{*}{ Partition $^{\mathrm{a}}$} & $K_{p}\left(\mathrm{Lg}^{-1}\right)$ & 1.185 & 0.995 & 0.924 \\
\hline & $R^{2}$ & 0.985 & 0.974 & 0.987 \\
\hline & $\chi^{2}$ & 9.834 & 16.595 & 14.609 \\
\hline & $A R E(\%)$ & 5.445 & 10.642 & 7.497 \\
\hline & $A I C$ & 42.128 & 45.490 & 39.860 \\
\hline
\end{tabular}

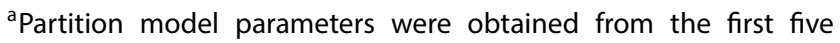
experimental points

regions including hydrophobic parts associated to carbon tail of the ammonium salt, and hydrophilic parts associated to the montmorillonite mineral nature, we expected that the 2,4-D can access different sites on the nanoclay surface. Thus, Freundlich model was chosen to describe the adsorption process. Also, when the temperature increase, the fitness of the models are improved. The calculated equilibrium parameter $\mathrm{n}$ parameter from the Freundlich model $(n>1)$ for all temperatures indicates that the process is favorable, almost linear.

Since the 2,4-D adsorption is a temperature dependent process, we can calculate the thermodynamic parameters of herbicide adsorption to understand the process, verifying the feasibility and the nature of adsorbate-adsorbent interactions $[28,39]$. The enthalpy change $\left(\Delta H^{\circ}\right)$, entropy change $\left(\Delta S^{\circ}\right)$, and Gibbs free energy change $\left(\Delta G^{\circ}\right)$ of the adsorption process can be calculated from Eqs. (20) and (21):

$\ln \left(K_{p}\right)=\frac{\Delta S^{\circ}}{R}-\frac{\Delta H^{\circ}}{R T}$
Table 2 Thermodynamic parameters of the 2,4-D adsorption on the montmorillonite at the temperatures of 25,35 and $45^{\circ} \mathrm{C}$

\begin{tabular}{lllll}
\hline$\Delta H^{\circ}\left(\mathrm{kJ} \mathrm{mol}^{-1}\right)$ & $\Delta S^{\circ}\left(\mathrm{kJ} \mathrm{mol}^{-1} \mathrm{~K}^{-1}\right)$ & \multicolumn{4}{l}{$\Delta G^{\circ}\left(\mathrm{kJ} \mathrm{mol}^{-1}\right)$} & \\
\cline { 2 - 5 } & & $25^{\circ} \mathrm{C}$ & $35^{\circ} \mathrm{C}$ & $45^{\circ} \mathrm{C}$ \\
\hline-9.849 & -0.032 & -0.383 & -0.066 & 0.252 \\
\hline & & & \\
$\Delta G^{\circ}=\Delta H^{\circ}-T \Delta S^{\circ}$
\end{tabular}

As can be seen in Fig. 1, for low equilibrium concentrations (up to $150 \mathrm{mg} \mathrm{L}^{-1}$ ), the adsorption isotherms are practically linear for all temperatures, suggesting that the adsorption occurred by a partition process. In this case, the $K_{p}$ constant associated to the adsorptive process can be obtain from Eq. (5), and the thermodynamic parameters associated with the 2,4-D adsorption occurring in low concentrations can be calculated.

The calculated thermodynamic parameters are shown in Table 2. The $\Delta G^{\circ}$ values are negative at 25 and $35^{\circ} \mathrm{C}$, indicating that the 2,4-D adsorption is favored in the equilibrium at these temperatures. However, the temperature increase from 35 to $45^{\circ} \mathrm{C}$ makes $\Delta G^{\circ}$ change from negative to positive, indicating that higher temperatures make the adsorption process unfavorable [40]. The negative values of $\Delta H^{\circ}$ and $\Delta S^{\circ}$ indicate that the adsorption process is exothermic, with the randomness being decreased during the transfer of the 2,4-D from the solution to the interface, i.e., the degrees of freedom of the adsorbed molecules is reduced [41, 42]. Also, $\Delta H^{\circ}$ value is smaller than $40 \mathrm{~kJ} \mathrm{~mol}^{-1}$, indicating that the adsorption mechanism is of physical nature (physisorption) [41]. Despite the equilibrium of the adsorption process is displaced to the adsorbed form of $2,4-\mathrm{D}$ at $45^{\circ} \mathrm{C}$, the isotherm study clearly indicates the high adsorption capacity of the nanoclay at this temperature. Probably, as the temperature increases, the transference of 2,4-D to the nanoclay becomes unfavorable due to the reduction of the hydrophobic contribution associated to the incorporation of the adsorbate into the hydrophobic region formed by the carbonic chains.

Although it was not possible to establish a maximum adsorption value for the material evaluated in this study, the values obtained experimentally in the concentration range investigated were much higher than the maximum adsorbed amount reported in the literature using clay or similar materials for 2,4-D adsorption, as shown in Table 3. This comparison indicates the high potential of the material as a 2,4-D adsorbent material, in which low quantities of adsorbent are necessary to adsorb high quantities of adsorbate. Also, it is expected a similar adsorption capacity for herbicides categorized as phenoxy herbicides, like the 
Table 3 Comparison of adsorption capacities with the literature

\begin{tabular}{lllll}
\hline Adsorbent & Modifier & $q\left(\mathrm{mg} \mathrm{g}^{-1}\right)^{\mathrm{a}}$ & $\mathrm{pH}$ & References \\
\hline $\begin{array}{lllll}\text { Montmoril- } \\
\text { lonite }\end{array}$ & $\begin{array}{c}\text { Quaternary } \\
\text { ammo- } \\
\text { nium salt }\end{array}$ & 282.87 & 2 & This study \\
Zeolite HY & - & 175.44 & 3 & {$[44]$} \\
& HDTMA & 82.64 & & \\
Montmoril- & - & 120.48 & & [12] \\
lonite & HDTMA & 158.73 & & \\
& DODAB & 161.29 & & [12] \\
Bentonite & - & 121.95 & 7 & \\
& HDTMA & 129.87 & & \\
Palygorskite & ODTMA & 42.02 & Non- & [45] \\
& DODAB & 133.33 & & \\
\hline
\end{tabular}

${ }^{a}$ In this study, the reported value refers to the highest experimental adsorption capacity obtained. Other values correspond to maximum adsorption capacity obtained from Langmuir model

2-methyl-4-chlorophenoxyacetic acid (MCPA) and the Dichlorprop, that has a similar chemical structure to that of the 2,4-D [43]. This property widens the applicability of the proposed system to water treatment applications. However, to extend this system applications to processes involving 2,4-D controlled release, kinetic studies are necessary.

\subsubsection{Kinetic}

Since saturation was not observed from the 2,4-D adsorption studies, the concentration of $4000 \mu \mathrm{mol} \mathrm{L}^{-1}$ and temperature of $25^{\circ} \mathrm{C}$ were selected for the kinetic studies. These studies were performed at $\mathrm{pH} 2,3$, and 4 at $25^{\circ} \mathrm{C}$, and the plots are shown in Fig. 2.

The analysis of the kinetic curves shows that the 2,4-D adsorption is very fast, with most of it occurring in the first $5 \mathrm{~min}$ and reaching the equilibrium within $30 \mathrm{~min}$ of contact. Additionally, the change in $\mathrm{pH}$ does not change the kinetic profile neither the adsorption capacity at the equilibrium. As seen in the zeta potential analysis (Fig. S1), at $\mathrm{pH} 2$ the montmorillonite is positively charged ( $\mathrm{PCZ}$ between $\mathrm{pH} 4$ and 5), while the most of 2,4-D species are neutral (pKa $\approx 2.7$ ). However, as the $\mathrm{pH}$ increases to 4, 2,4-D molecules are deprotonated, and the montmorillonite positive charge is decreased. Thus, our result suggests that, in the range of $\mathrm{pH}$ evaluated, there should be a compensatory effect on the charge of the species interacting that promotes a non-important change in the magnitude of the electrostatic interactions as the $\mathrm{pH}$ increases and that 2,4-D adsorption should be maximized in $\mathrm{pHs} \leq 4$.
The parameters of the kinetic models utilized for the $\mathrm{pH}$ of 2, 3, and 4 are shown in Table 4, and the fitted models are shown in Fig. 2. From the models utilized to describe the 2,4-D adsorption over time, the pseudo-first-order and the pseudo-second-order models were the best ones with coefficient of determination $R^{2}$ higher than 0.99 , in which both describe the high initial adsorption. However, the pseudo-second-order was the best fitted model because it presented adsorption capacities closer to the experimental, having the highest values of coefficient of determination $R^{2}$ and the lowest values of Chi square $\chi^{2}$, $A R E$, and $A I C$, indicating that the best interpretation of the process is that it is chemically rate-controlled, i.e., the process is of chemical nature (chemisorption) [27, 31, 41]. Chemisorption is usually irreversible and primarily based on electrostatic forces [46], which contradicts the results obtained from the thermodynamic parameters. This contradiction indicates that the mechanism that best describe the 2,4-D adsorption on the nanoclay is, in fact, a mixture of physisorption and chemisorption processes. This combination of mechanisms, involving weak and strong forces governing the process, suggests that the 2,4-D adsorption occurs on the hydrophobic and hydrophilic regions of the nanoclay.

As for the intraparticle model, it did not show good applicability due the poor fit of the experimental data with the lowest value of coefficient of determination $R^{2}$ and as the fitted model did not pass through the origin, contradicting the model assumption [31]. Thus, the prediction that the rate-limiting step is an intraparticle diffusion is not applicable.

\subsection{Characterization of the nanoclay/2,4-D system}

\subsubsection{Adsorption efficiency and $\mathrm{N}_{2}$ adsorption analysis}

As shown by the adsorption studies, the temperature of $25^{\circ} \mathrm{C}$ and $\mathrm{pH} 2$ were selected as the best conditions to obtain the highest amount possible of 2,4-D adsorbed on the nanoclay. Also, as there is no saturation on the range of concentration studied, the herbicide concentration and nanoclay utilized was $4000 \mu \mathrm{mol} \mathrm{L}^{-1}$ and $2 \mathrm{mg} \mathrm{mL}^{-1}$, respectively. The percentage of 2,4-D adsorbed on the nanoclay, $A E$, was $64.42 \pm 2.66 \%$. This percentage means that from the $4000 \mu \mathrm{mol} \mathrm{L^{-1 }}$ initially available in the adsorption medium, approximately $2500 \mu \mathrm{mol} \mathrm{L}^{-1}$ were adsorbed on the nanoclay with an adsorption capacity of approximately $286.02 \mathrm{mg} \mathrm{g}^{-1}\left(644.18 \mu \mathrm{mol} \mathrm{g}{ }^{-1}\right)$, i.e., approximately $24.45 \%$ of the final mass correspond to 2,4-D.

The specific surface area $S_{B E T}$, the total pore volume and the average pore diameter $4 \mathrm{~V} / S_{B E T}$ of the pristine montmorillonite (MMT), the control sample and the nanoclay 

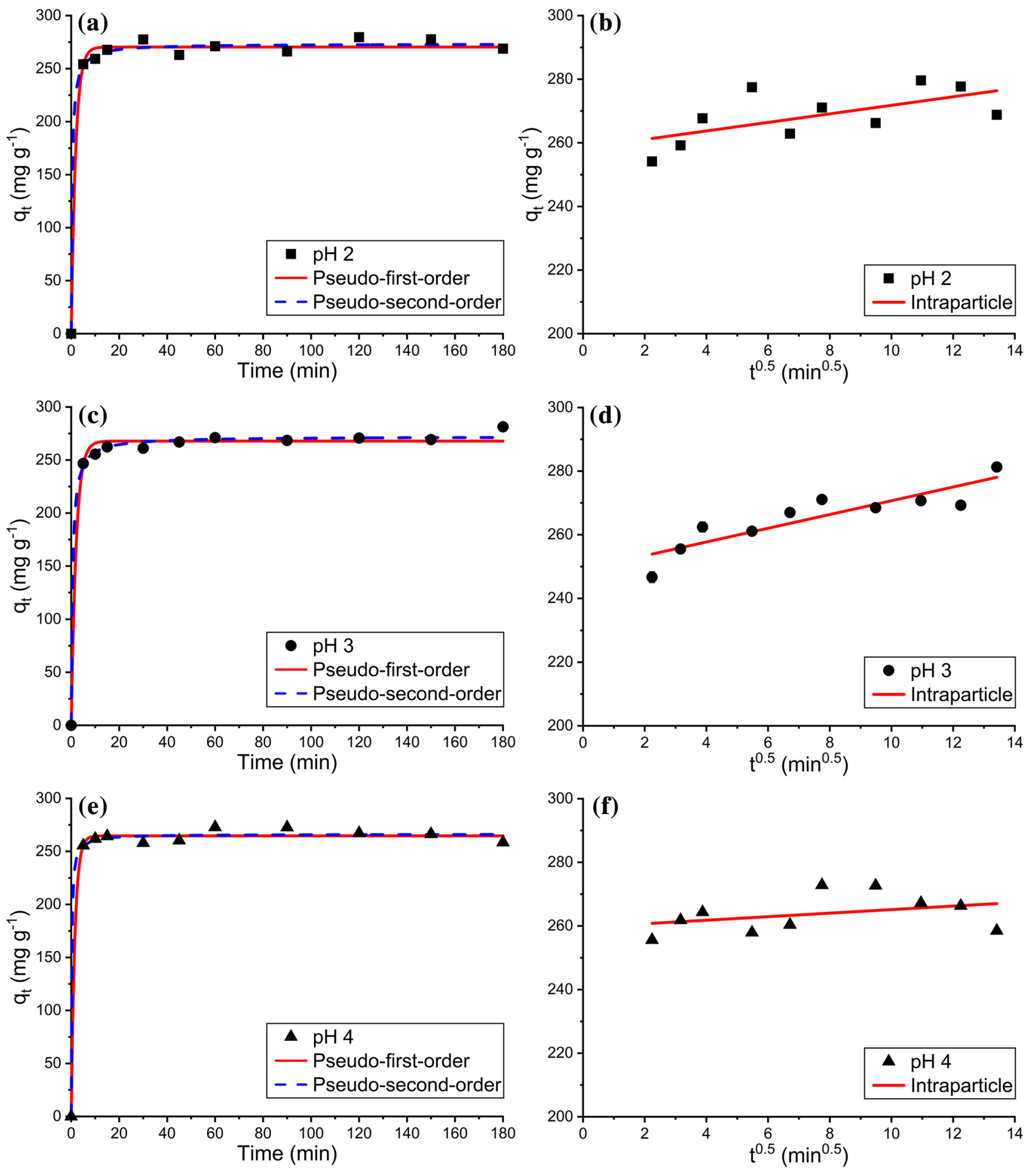

Fig. 2 Kinetic data for the 2,4-D adsorption on the montmorillonite at pH 2 (a), 3 (c) and 4 (e) in $25^{\circ} \mathrm{C}$ fitted to the pseudo-first and pseudosecond-order models and to the intraparticle model at $\mathrm{pH} 2$ (b), 3 (d) and 4 (f)

with 2,4-D adsorbed (MMT + 2,4-D) are shown in Table 5. As seen from the results, the processing conditions of the nanoclay does not induce any significant changes in its structure, since none significant change was observed in the $S_{B E T}$ value. However, the treatment of the sample causes the elimination of some mesopores, reducing the total pore volume and the average pore diameter, which suggests a possible change in the hydrocarbonic 
Table 4 Parameters of the pseudo-first-order, pseudo-secondorder and intraparticle models applied to the 2,4-D adsorption on the montmorillonite at $\mathrm{pH} 2,3$ and 4

\begin{tabular}{|c|c|c|c|c|}
\hline \multirow[t]{2}{*}{ Model } & \multirow[t]{2}{*}{ Parameter } & \multicolumn{3}{|l|}{$\mathrm{pH}$} \\
\hline & & 2 & 3 & 4 \\
\hline \multirow{6}{*}{$\begin{array}{l}\text { Pseudo-first- } \\
\text { order }\end{array}$} & $q_{e}\left(\mathrm{mg} \mathrm{g}^{-1}\right)$ & 270.37 & 267.88 & 264.74 \\
\hline & $K_{1}\left(\min ^{-1}\right)$ & 0.547 & 0.490 & 0.670 \\
\hline & $R^{2}$ & 0.994 & 0.994 & 0.996 \\
\hline & $\chi^{2}$ & 1.391 & 1.445 & 0.941 \\
\hline & ARE (\%) & 1.913 & 1.750 & 1.535 \\
\hline & $A I C$ & 41.971 & 42.242 & 37.872 \\
\hline \multirow{6}{*}{$\begin{array}{l}\text { Pseudo-second- } \\
\text { order }\end{array}$} & $q_{e}\left(\mathrm{mg} \mathrm{g}^{-1}\right)$ & 273.43 & 272.17 & 266.26 \\
\hline & $K_{2}\left(\mathrm{mg} \mathrm{g}^{-1} \min ^{-1}\right)$ & 0.009 & 0.006 & 0.019 \\
\hline & $R^{2}$ & 0.996 & 0.998 & 0.996 \\
\hline & $\chi^{2}$ & 0.994 & 0.586 & 0.874 \\
\hline & ARE (\%) & 1.649 & 1.033 & 1.431 \\
\hline & $A I C$ & 38.648 & 33.285 & 37.153 \\
\hline \multirow[t]{6}{*}{ Intraparticle } & $\begin{array}{c}k_{i d}\left(\mathrm{mg} \mathrm{g}^{-1}\right. \\
\left.\min ^{-0.5}\right)\end{array}$ & 1.337 & 2.151 & 0.553 \\
\hline & $C\left(\mathrm{mg} \mathrm{g}^{-1}\right)$ & 257.265 & 248.013 & 258.470 \\
\hline & $R^{2}$ & 0.397 & 0.789 & 0.131 \\
\hline & $\chi^{2}$ & 1.408 & 0.654 & 1.079 \\
\hline & ARE (\%) & 2.054 & 1.295 & 1.631 \\
\hline & $A I C$ & 42.021 & 34.193 & 39.226 \\
\hline
\end{tabular}

Table 5 Structure characteristics of the samples obtained from $\mathrm{N}_{2}$ adsorption

\begin{tabular}{llll}
\hline Sample & $\begin{array}{l}\text { Specific surface } \\
\text { area } S_{B E T}\left(\mathrm{~m}^{2}\right. \\
\left.\mathrm{g}^{-1}\right)\end{array}$ & $\begin{array}{l}\text { Total pore } \\
\text { volume }\left(\mathrm{cm}^{3}\right. \\
\left.\mathrm{g}^{-1}\right)\end{array}$ & $\begin{array}{l}\text { Average pore } \\
\text { diameter } 4 \mathrm{~V} / S_{B E T} \\
(\mathrm{~nm})\end{array}$ \\
\hline Pristine MMT & 1.2282 & 0.0114 & 37.0782 \\
Control MMT & 1.2331 & 0.0066 & 21.3241 \\
MMT+2,4-D & 0.6894 & 0.0003 & 1.6681 \\
\hline
\end{tabular}

conformation of the ammonium salt. On the other hand, the 2,4-D adsorption causes a reduction of $S_{B E T}$, which probably means that the 2,4-D molecules begin to occupy the materials pores, making them inaccessible to the nitrogen molecules during the $\mathrm{N}_{2}$ adsorption analysis. This is corroborated by the amount of total pore volume and average pore diameter that are reduced with the adsorption, meaning that almost all pores were filled and that only microporous not accessed by 2,4-D are left.

\subsubsection{Structural analysis}

The XRD patterns of the pristine montmorillonite, control sample and nanoclay with 2,4-D adsorbed are shown in Fig. 3. As seen from the XRD patterns, the position of the (001) diffraction plane shifts from $5.12^{\circ}$ to $5.22^{\circ}$, when the

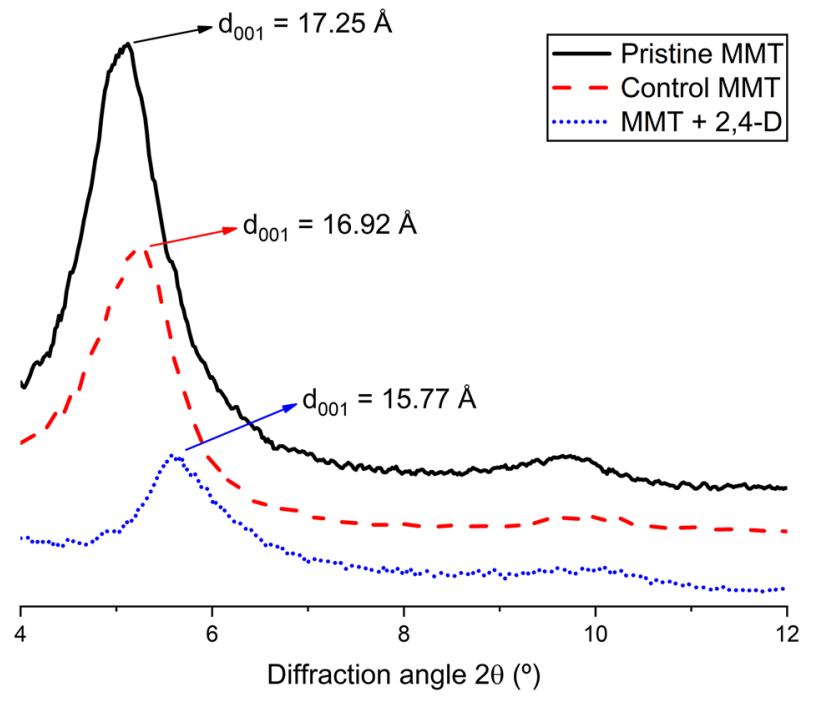

Fig. 3 XRD patterns of the samples

montmorillonite is submitted to the process conditions and to the obtaining method, that is related to a small decrease in the basal spacing of the nanoclay (from 17.25 to $16.92 \AA$ ). This decrease is probably related to a change in the quaternary ammonium salt conformation on the interlayer space. As for the sample with 2,4-D adsorbed, the position of the (001) diffraction plane shifted from $5.12^{\circ}$ to $5.60^{\circ}$, which means that the basal spacing of the nanoclay is reduced from 17.25 to $15.77 \AA$. This shift and the noticeable decrease in the peak intensity is related to the partial exfoliation of the clay structure probably due to the high concentration of 2,4-D adsorbed $[47,48]$.

The FTIR spectra of the pristine montmorillonite, control sample, nanoclay with 2,4-D adsorbed and pure 2,4-D are shown in Fig. 4a, b. The montmorillonite spectrum presents the characteristics bands at $1047 \mathrm{~cm}^{-1}$ (Si-O stretching), $625 \mathrm{~cm}^{-1}$ (Coupled Al-O and $\mathrm{Si}-\mathrm{O}$ out of plane vibrations), $522 \mathrm{~cm}^{-1}$ (Al-O-Si deformation) and $465 \mathrm{~cm}^{-1}$ (Si-O-Fe deformation) [49]. The organically modification (introduction of the quaternary ammonium salt) of the montmorillonite is also visible on the FTIR spectrum (Fig. 4a) with the vibration bands at $2926 \mathrm{~cm}^{-1}$ (asymmetric $\mathrm{CH}_{3}$ stretching) and $2855 \mathrm{~cm}^{-1}$ (symmetric $\mathrm{CH}_{2}$ stretching) [50]. From the comparison between pristine and control montmorillonite samples, no significant change is observed in the spectra, proving that the process conditions and the obtaining method did not induce any significant changes in the material structure.

For the nanoclay with 2,4-D adsorbed, the FTIR spectra shows that the adsorption process did not modify the characteristics bands of the montmorillonite. The adsorption process is proven with the appearance of new vibration bands or strengthen of already existed ones, that are 

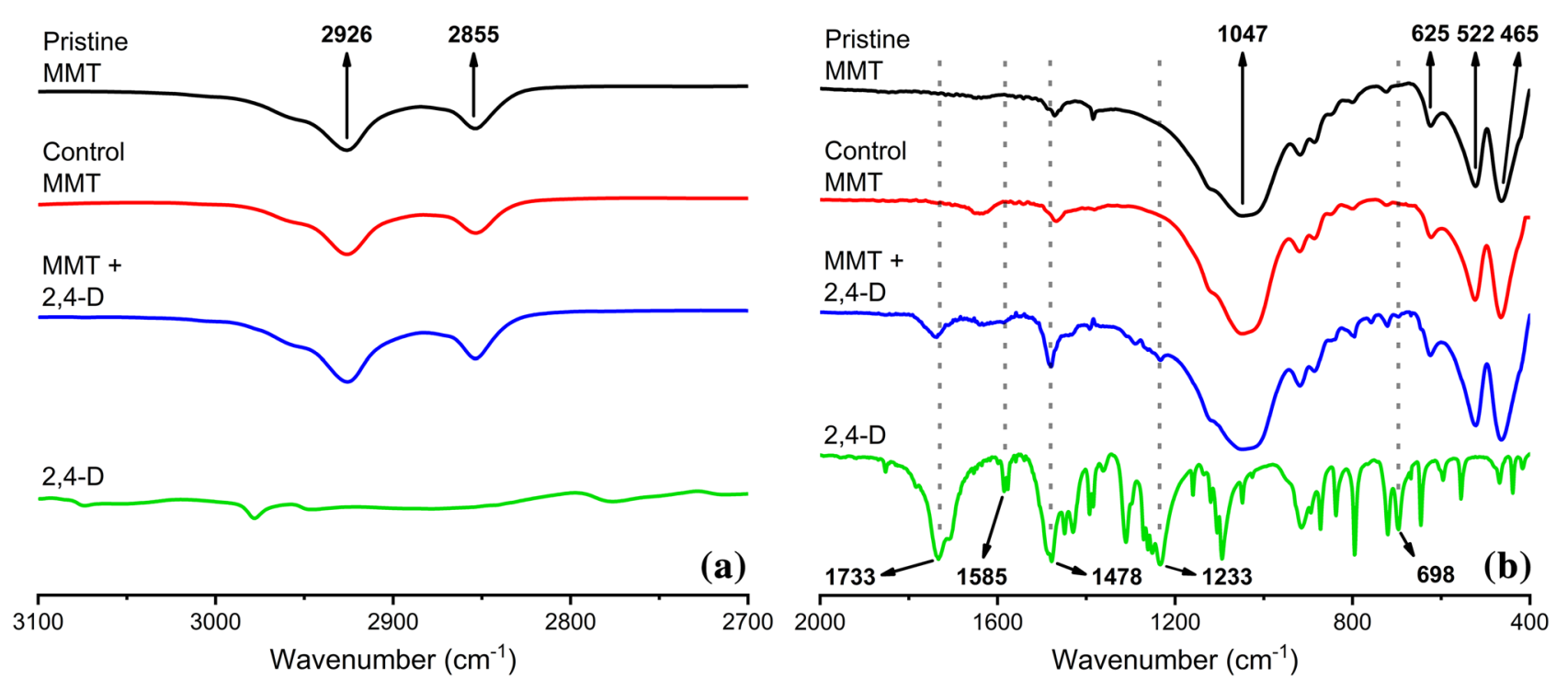

Fig. 4 FTIR spectra of the samples

characteristics to the 2,4-D sample. The characteristics bands of the herbicide are $1733 \mathrm{~cm}^{-1}$ ( $C=O$ stretching), $1585 \mathrm{~cm}^{-1}$ and $1478 \mathrm{~cm}^{-1}$ ( $\mathrm{C}=\mathrm{C}$ vibrations of the aromatic ring), $1233 \mathrm{~cm}^{-1}$ (coupled $\mathrm{C}-\mathrm{O}$ and $\mathrm{O}-\mathrm{H}$ stretching) and $698 \mathrm{~cm}^{-1}$ (C-Cl stretching) $[11,51,52]$. As there was not displacement in the position of the 2,4-D characteristic bands on the 2,4-D + MMT spectra, it is suggested that there was not formation of covalent bonds between the 2,4-D and the nanoclay surface.

\subsection{Release study}

To evaluate the release mechanism of 2,4-D adsorbed on the nanoclay, approximately $550 \mathrm{mg}$ of sample, that contains approximately $135.75 \mathrm{mg}$ of 2,4-D, was dispersed in $100 \mathrm{~mL}$ of aqueous solution of ethanol $(3 \% \mathrm{v} / \mathrm{v})$, i.e., the herbicide concentration to be released was approximately $600 \mu \mathrm{mol} \mathrm{L}{ }^{-1}$. To stimulate the release, the solution $\mathrm{pH}$ was adjusted to 6 with $\mathrm{KOH}$ solution. As it was seen from the preliminary zeta potential characterization (Supporting information S1), in $\mathrm{pH} 6$ the superficial charges of the montmorillonite and the 2,4-D are negative, and repulsion between the materials is expected, favoring the release. The 2,4-D release profile in pH 6 is shown in Fig. 5.

From the release profile data, it is possible to visualize a 2,4-D high burst release on the medium, with $63.57 \pm 1.46 \%$ of the herbicide being released in first $5 \mathrm{~min}$ of contact, following by a slow release with $77.87 \pm 1.79 \%$ after 2 days ( $2880 \mathrm{~min}$ ) of experiment. The high burst release is probably due to the $\mathrm{pH}$ adjustment, that provides opposite charges to the nanoclay and 2,4-D, combined to the high adsorption capacity of the nanoclay, making the 2,4-D to have a more favorable interaction with

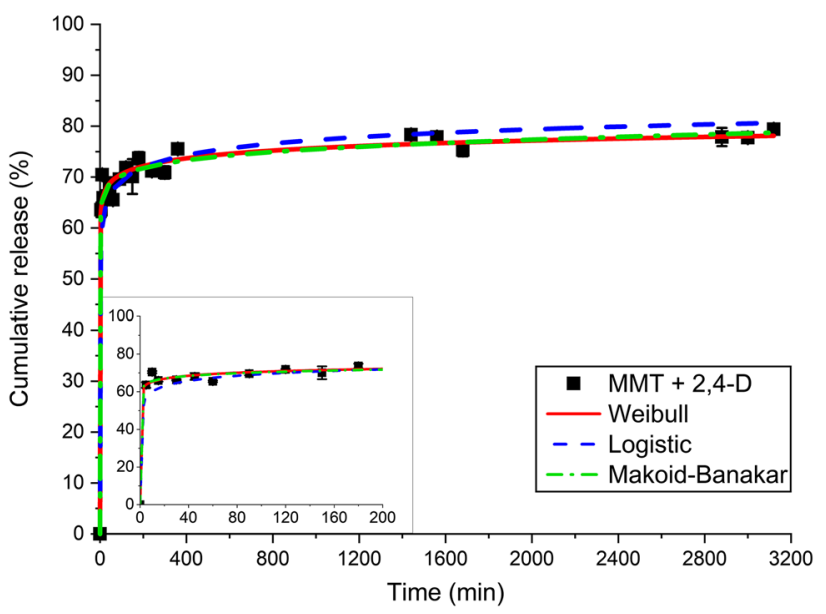

Fig. 5 Release profile data of 2,4-D adsorbed on the montmorillonite at $\mathrm{pH} 2$ and $25^{\circ} \mathrm{C}$ fitted to the Weibull, Logistic and MakoidBanakar models. Inset: magnification of the curve for smaller time intervals

the solvent than that with the montmorillonite, releasing the high quantity of weaker bonded 2,4-D molecules from the hydrophophic region.

The release profile obtained in this study, i.e., a high burst followed by a slow release, is similar to those previously reported in the literature that used 2,4-D as adsorbate and clay materials as adsorbents (layered double hydroxides (LDH), also called anionic clays, and others organically modified clay, for instance [53-55]), that were aimed to be applied as herbicide controlled release formulations. Despite the similarity, the release studies performed by Ragavan et al. [53], Bashi et al. [54], and Hermosín et al. [55] reached equilibrium in approximately 
100-1440 min (1 day), while in this work the equilibrium was not reached in the time range studied. According to the release models applied to our data (Weibull, Logistic and Makoid-Banakar), shown in Fig. 5, the equilibrium is still far to be reached. Besides, the release profile described in this study corroborates the initial hypothesis indicated by the adsorption mechanism, that was related to a burst and a controlled release.

The parameters of the release models utilized are shown in Table 6, and the fitted models are plotted in Fig. 5. The Makoid-Banakar model best described the release profile with higher coefficient of determination $R^{2}(>0.98)$ and lower values of Chi square $\chi^{2}, A R E$ and $A I C$. The models of Zero-order, First-order, Higuchi, Hixson-Crowell and Korsmeyer-Peppas were also applied to the release profile but did not fit the data properly $\left(R^{2}<0.70\right)$.

\section{Conclusions}

The results showed the high 2,4-D adsorption capacity of the organically modified montmorillonite. The adsorption studies showed that in the concentration range utilized, the equilibrium was reached in $30 \mathrm{~min}$, being that, in the concentration range evaluated $\left(500-4000 \mu \mathrm{mol} \mathrm{L}^{-1}\right)$, no adsorption saturation was observed. The adsorption process was slightly dependent on temperature. The best

Table 6 Parameters of the Weibull, Logistic and Makoid-Banakar models applied to the 2,4-D release profile

\begin{tabular}{lll}
\hline Model & Parameter & $2,4-\mathrm{D}$ release \\
\hline Weibull & $a$ & 1.091 \\
& $b$ & 0.063 \\
& $T_{1}(\mathrm{~min})$ & $3.369 \times 10^{-9}$ \\
& $R^{2}$ & 0.987 \\
$\chi^{2}$ & 1.019 \\
& $A R E(\%)$ & 2.088 \\
& $A / C$ & 32.542 \\
Logistic & $a$ & -0.013 \\
& $b$ & 0.190 \\
& $R^{2}$ & 0.958 \\
& $\chi^{2}$ & 3.591 \\
& $A R E(\%)$ & 3.600 \\
& $A I C$ & 51.733 \\
$k_{M B}$ & 0.614 \\
$n$ & $k$ & 0.029 \\
& $k$ & $-4.146 \times 10^{-6}$ \\
$R^{2}$ & 0.988 \\
$\chi^{2}$ & 0.957 \\
$A R E(\%)$ & 2.117 \\
$A I C$ & 31.402 \\
\hline & &
\end{tabular}

fitted models were the Freundlich and the pseudo-second order for the isotherm and kinetic studies, respectively. The determination of the thermodynamic parameters of adsorption and kinetic studies indicated that the adsorption mechanism probably involved physisorption and chemisorption. The characterizations analyses showed that the high concentration of 2,4-D adsorbed caused a partial exfoliation of the montmorillonite structure. The release profile of the 2,4-D adsorbed showed a high initial burst release followed by a slow one. These results indicated the usability of the organically modified montmorillonite nanoclays as 2,4-D adsorbents, expanding its range of applications in controlled release systems to be applied as herbicide or phytohormone, or even in water treatment systems.

Acknowledgements The authors are grateful to the Universidade Federal de Lavras (UFLA), Fundação de Amparo à Pesquisa do Estado de Minas Gerais (FAPEMIG), Conselho Nacional de Desenvolvimento Científico e Tecnológico (CNPq), MCTI-SisNano, FINEP, Nanotechnology National Laboratory for Agriculture, EMBRAPA Instrumentação, and the Coordenação de Aperfeiçoamento de Pessoal de Nível Superior (CAPES) for the financial support.

Funding This study was funded by Fundação de Amparo à Pesquisa do Estado de Minas Gerais (FAPEMIG - Grant Numbers: APQ-0150515, APQ-00906-17) and Conselho Nacional de Desenvolvimento Científico e Tecnológico (CNPq - Grant Numbers: 402287/2013-4, 302044/2015-9, 403357/2016-0, 302469/2018-4).

\section{Compliance with ethical standards}

Conflict of interest The authors declare that they have no conflict of interest.

\section{References}

1. Huang W, Chen J, He F, Tang J, Li D, Zhu Y, Zhang Y (2015) Effective phosphate adsorption by $\mathrm{Zr} / \mathrm{Al}$-pillared montmorillonite: insight into equilibrium, kinetics and thermodynamics. Appl Clay Sci 104:252-260. https://doi.org/10.1016/j.clay.2014.12.002

2. Magaña SM, Quintana $\mathrm{P}$, Aguilar DH, Toledo JA, ÁngelesChávez C, Cortés MA, León L, Freile-Pelegrín Y, López T, Sánchez RMT (2008) Antibacterial activity of montmorillonites modified with silver. J Mol Catal A Chem 281:192-199. https://doi. org/10.1016/j.molcata.2007.10.024

3. Kotal M, Bhowmick AK (2015) Polymer nanocomposites from modified clays: recent advances and challenges. Prog Polym Sci 51:127-187.

4. Dähn R, Scheidegger AM, Manceau A, Schlegel ML, Baeyens B, Bradbury MH, Chateigner D (2003) Structural evidence for the sorption of $\mathrm{Ni}$ (II) atoms on the edges of montmorillonite clay minerals: a polarized X-ray absorption fine structure study. Geochim Cosmochim Acta 67:1-15. https://doi.org/10.1016/S0016 -7037(02)01005-0

5. de Paiva LB, Morales AR, Valenzuela Díaz FR (2008) Organoclays: properties, preparation and applications. Appl Clay Sci 42:8-24. https://doi.org/10.1016/j.clay.2008.02.006 
6. Wang L, Wang A (2008) Adsorption properties of Congo Red from aqueous solution onto surfactant-modified montmorilIonite. J Hazard Mater 160:173-180. https://doi.org/10.1016/j. jhazmat.2008.02.104

7. Aguzzi C, Cerezo P, Viseras C, Caramella C (2007) Use of clays as drug delivery systems: possibilities and limitations. Appl Clay Sci 36:22-36. https://doi.org/10.1016/j.clay.2006.06.015

8. Rytwo G, Ben Moshe S (2017) Evaporation of allyl isothiocyanate from clay minerals and organoclays. Appl Clay Sci 137:30-32. https://doi.org/10.1016/j.clay.2016.12.007

9. Tejada M, Morillo E, Gómez I, Madrid F, Undabeytia T (2017) Effect of controlled release formulations of diuron and alachlor herbicides on the biochemical activity of agricultural soils. J Hazard Mater 322:334-347. https://doi.org/10.1016/j.jhazm at.2016.10.002

10. Tchoumene R, Kenne Dedzo G, Ngameni E (2018) Preparation of methyl viologen-kaolinite intercalation compound: controlled release and electrochemical applications. ACS Appl Mater Interfaces 10:34534-34542. https://doi.org/10.1021/acsami.8b13953

11. Bartczak P, Żółtowska S, Norman M, Klapiszewski Ł, Zdarta J, Komosa A, Kitowski I, Ciesielczyk F, Jesionowski T (2016) Sawsedge Cladium mariscus as a functional low-cost adsorbent for effective removal of 2,4-dichlorophenoxyacetic acid from aqueous systems. Adsorption 22:517-529. https://doi.org/10.1007/ s10450-015-9708-2

12. Bhardwaj D, Sharma P, Sharma M, Tomar R (2014) Surfactant modified tectosilicates and phyllosilicates for 2,4-D removal and slow release formulation. RSC Adv 4:4504-4514. https:// doi.org/10.1039/C3RA44121K

13. Grover R, Maybank J, Yoshida K (1972) Droplet and vapor drift from butyl butyl ester and dimethylamine salt of 2,4-D. Weed Sci 20:320-324

14. Islam F, Wang J, Farooq MA, Khan MSS, Xu L, Zhu J, Zhao M, Muños S, Li QX, Zhou W (2018) Potential impact of the herbicide 2,4-dichlorophenoxyacetic acid on human and ecosystems. Environ Int 111:332-351. https://doi.org/10.1016/j.envin t.2017.10.020

15. Weber JB, Perry PW, Upchurch RP (1965) The influence of temperature and time on the adsorption of paraquat, diquat, 2,4-D and prometone by clays, charcoal, and an anion-exchange resin 1. Soil Sci Soc Am J 29:678. https://doi.org/10.2136/sssaj 1965.03615995002900060026x

16. Haque R, Lindstrom FT, Freed VH, Sexton R (1968) Kinetic study of the sorption of 2,4-D on some clays. Environ Sci Technol 2:207-211. https://doi.org/10.1021/es60015a002

17. Ogram AV, Jessup RE, Ou LT, Rao PSC (1985) Effects of sorption on biological degradation rates of (2,4-dichlorophenoxy)acetic acid in soils. Appl Environ Microbiol 49:582-587

18. Celis R, Hermosín MC, Carrizosa MJ, Cornejo J (2002) Inorganic and organic clays as carriers for controlled release of the herbicide hexazinone. J Agric Food Chem 50:2324-2330. https://doi. org/10.1021/jf011360o

19. Langmuir I (1918) The adsorption of gases on plane surfaces of glass, mica and platinum. J Am Chem Soc 40:1361-1403. https ://doi.org/10.1021/ja02242a004

20. Hameed BH, Tan IAW, Ahmad AL (2008) Adsorption isotherm, kinetic modeling and mechanism of 2,4,6-trichlorophenol on coconut husk-based activated carbon. Chem Eng J 144:235-244. https://doi.org/10.1016/j.cej.2008.01.028

21. Freundlich $\mathrm{H}$ (1907) Über die adsorption in Lösungen. Zeitschrift für Phys Chemie 57U:385-470. https://doi.org/10.1515/ zpch-1907-5723

22. Ma Y, Lv L, Guo Y, Fu Y, Shao Q, Wu T, Guo S, Sun K, Guo X, Wujcik EK, Guo Z (2017) Porous lignin based poly (acrylic acid)/organomontmorillonite nanocomposites: swelling behaviors and rapid removal of $\mathrm{Pb}$ (II) ions. Polymer (Guildf) 128:12-23. https://doi. org/10.1016/j.polymer.2017.09.009

23. Bouabidi ZB, El-Naas MH, Cortes D, McKay G (2018) Steel-making dust as a potential adsorbent for the removal of lead (II) from an aqueous solution. Chem Eng J 334:837-844. https://doi. org/10.1016/j.cej.2017.10.073

24. Dubinin MM, Radushkevich LV (1947) Equation of the characteristic curve of the activated charcoal. Proc Natl Acad Sci USSR Phys Chem Sect 55:331-333

25. Limousin G, Gaudet JP, Charlet L, Szenknect $S$, Barthès V, Krimissa $M$ (2007) Sorption isotherms: a review on physical bases, modeling and measurement. Appl Geochem 22:249-275. https ://doi.org/10.1016/j.apgeochem.2006.09.010

26. Lagergren S (1898) Zur theorie der sogenannten adsorption geloster stoffe. K Sven vetenskapsakademiens Handl 24:1-39

27. Ho YS, McKay G (1999) Pseudo-second order model for sorption processes. Process Biochem 34:451-465. https://doi. org/10.1016/S0032-9592(98)00112-5

28. Maneerung T, Liew J, Dai Y, Kawi S, Chong C, Wang C-H (2016) Activated carbon derived from carbon residue from biomass gasification and its application for dye adsorption: kinetics, isotherms and thermodynamic studies. Bioresour Technol 200:350359. https://doi.org/10.1016/j.biortech.2015.10.047

29. Weber WJ, Morris JC (1963) Kinetics of adsorption on carbon from solution. J Sanit Eng Div 89:31-60

30. Kavitha D, Namasivayam C (2007) Experimental and kinetic studies on methylene blue adsorption by coir pith carbon. Bioresour Technol 98:14-21. https://doi.org/10.1016/j.biort ech.2005.12.008

31. Djebbi MA, Boubakri S, Bouaziz Z, Elayachi MS, Namour $P_{1}$ Jaffrezic-Renault N, Ben Haj Amara A (2018) Extended-release of chlorpromazine intercalated into montmorillonite clays. Microporous Mesoporous Mater 267:43-52. https://doi. org/10.1016/j.micromeso.2018.03.017

32. Dash S, Murthy PN, Nath L, Chowdhury P (2010) Kinetic modeling on drug release from controlled drug delivery systems. Acta Pol Pharm 67:217-223

33. Langenbucher $F$ (1972) Linearization of dissolution rate curves by the Weibull distribution. J Pharm Pharmacol 24:979-981. https://doi.org/10.1111/j.2042-7158.1972.tb08930.x

34. Sathe PM, Tsong Y, Shah VP (1996) In-vitro dissolution profile comparison: statistics and analysis, model dependent approach. Pharm Res 13:1799-1803. https://doi.org/10.1023/A:10160 20822093

35. Karami Z, Sadighian S, Rostamizadeh K, Parsa M, Rezaee S (2016) Naproxen conjugated mPEG-PCL micelles for dual triggered drug delivery. Mater Sci Eng C 61:665-673. https://doi. org/10.1016/j.msec.2015.12.067

36. Dotto GL, Costa JAV, Pinto LAA (2013) Kinetic studies on the biosorption of phenol by nanoparticles from Spirulina sp. LEB 18. J Environ Chem Eng 1:1137-1143. https://doi.org/10.1016/j. jece.2013.08.029

37. Giles CH, Smith D, Huitson A (1974) A general treatment and classification of the solute adsorption isotherm I. Theor J Colloid Interface Sci 47:755-765. https://doi.org/10.1016/00219797(74)90252-5

38. Acevedo S, Ranaudo MA, Escobar G, Gutiérrez L, Ortega P (1995) Adsorption of asphaltenes and resins on organic and inorganic substrates and their correlation with precipitation problems in production well tubing. Fuel 74:595-598. https:// doi.org/10.1016/0016-2361(95)98363-J

39. Inyinbor AA, Adekola FA, Olatunji GA (2016) Kinetics, isotherms and thermodynamic modeling of liquid phase adsorption of Rhodamine B dye onto Raphia hookerie fruit epicarp. Water Resour Ind 15:14-27. https://doi.org/10.1016/j.wri.2016.06.001 
40. Aktas D, Dizge N, Cengiz Yatmaz H, Caliskan Y, Ozay Y, Caputcu A (2017) The adsorption and Fenton behavior of iron rich Terra Rosa soil for removal of aqueous anthraquinone dye solutions: kinetic and thermodynamic studies. Water Sci Technol 76:31143125. https://doi.org/10.2166/wst.2017.468

41. Bekçi Z, Seki Y, Yurdakoç MK (2006) Equilibrium studies for trimethoprim adsorption on montmorillonite KSF. J Hazard Mater 133:233-242. https://doi.org/10.1016/j.jhazmat.2005.10.029

42. Hu C, Zhu P, Cai M, Hu H, Fu Q (2017) Comparative adsorption of $\mathrm{Pb}(\mathrm{II}), \mathrm{Cu}(\mathrm{II})$ and $\mathrm{Cd}(\mathrm{II})$ on chitosan saturated montmorillonite: kinetic, thermodynamic and equilibrium studies. Appl Clay Sci 143:320-326. https://doi.org/10.1016/j.clay.2017.04.005

43. Grossmann K (2010) Auxin herbicides: current status of mechanism and mode of action. Pest Manag Sci 66:113-120. https:// doi.org/10.1002/ps.1860

44. Pukcothanung $Y$, Siritanon T, Rangsriwatananon K (2018) The efficiency of zeolite $Y$ and surfactant-modified zeolite $Y$ for removal of 2,4-dichlorophenoxyacetic acid and 1,1"-dimethyl4,4"-bipyridinium ion. Microporous Mesoporous Mater 258:131140. https://doi.org/10.1016/j.micromeso.2017.08.035

45. Xi Y, Mallavarapu M, Naidu R (2010) Adsorption of the herbicide 2,4-D on organo-palygorskite. Appl Clay Sci 49:255-261. https ://doi.org/10.1016/j.clay.2010.05.015

46. Tsai T, Vesilind PA (1999) Zinc adsorption by lime-treated montmorillonite clay. J Environ Sci Heal A 34:103-124. https://doi. org/10.1080/10934529909376826

47. Kaur M, Datta M (2014) Diclofenac sodium adsorption onto montmorillonite: adsorption equilibrium studies and drug release kinetics. Adsorpt Sci Technol 32:365-387. https://doi. org/10.1260/0263-6174.32.5.365

48. Kaşgöz H, Durmuş A, Kaşgöz A (2008) Enhanced swelling and adsorption properties of AAm-AMPSNa/clay hydrogel nanocomposites for heavy metal ion removal. Polym Adv Technol 19:213-220. https://doi.org/10.1002/pat.999

49. Li S-Z, Wu P-X (2010) Characterization of sodium dodecyl sulfate modified iron pillared montmorillonite and its application for the removal of aqueous $\mathrm{Cu}(\mathrm{II})$ and $\mathrm{Co}(\mathrm{II})$. J Hazard Mater 173:6270. https://doi.org/10.1016/j.jhazmat.2009.08.047

50. Belver C, Aranda P, Martín-Luengo MA, Ruiz-Hitzky E (2012) New silica/alumina-clay heterostructures: properties as acid catalysts. Microporous Mesoporous Mater 147:157-166. https ://doi.org/10.1016/j.micromeso.2011.05.037

51. Trivedi NS, Kharkar RA, Mandavgane SA (2016) 2,4-Dichlorophenoxyacetic acid adsorption on adsorbent prepared from groundnut shell: effect of preparation conditions on equilibrium adsorption capacity. Arab J Chem. https://doi.org/10.1016/j. arabjc.2016.07.022

52. Pérez-Martínez Jl, Ginés JM, Morillo E, Rodríguez MLG, Moyano JR (2000) 2,4-Dichlorophenoxyacetic acid/partially methylated$\beta$-cyclodextrin inclusion complexes. Environ Technol 21:209216. https://doi.org/10.1080/09593330.2000.9618902

53. Ragavan A, Khan Al, O'Hare D (2006) Intercalation and controlled release of 2,4-dichlorophenoxyacetic acid using rhombohedral $\left[\mathrm{LiAl}_{2}(\mathrm{OH})_{6}\right] \mathrm{Cl}_{x} \mathrm{H}_{2} \mathrm{O}$. J Phys Chem Solids 67:983-986. https://doi. org/10.1016/j.jpcs.2006.01.076

54. Bashi AM, Hussein MZ, Zainal Z, Rahmani M, Tichit D (2016) Simultaneous intercalation and release of 2,4-dichloro- and 4-chloro-phenoxy acetates into $\mathrm{Zn} / \mathrm{Al}$ layered double hydroxide. Arab J Chem 9:S1457-S1463. https://doi.org/10.1016/j.arabj c.2012.03.015

55. Hermosín MC, Celis R, Facenda G, Carrizosa MJ, Ortega-Calvo $\mathrm{JJ}$, Cornejo J (2006) Bioavailability of the herbicide 2,4-D formulated with organoclays. Soil Biol Biochem 38:2117-2124. https ://doi.org/10.1016/j.soilbio.2006.01.032

Publisher's Note Springer Nature remains neutral with regard to jurisdictional claims in published maps and institutional affiliations. 